\title{
Time for a change: anticipating the diagnosis and treatment of COPD
}

\author{
Alvar Agusti ${ }^{1,2}$, Bernardino Alcazar (10,3 ${ }^{2,3}$, Borja Cosio $\mathbb{1}^{2,4}$, Jose Maria Echave ${ }^{5}$, \\ Rosa Faner ${ }^{2}$, Jose Luis Izquierdo ${ }^{6,7}$, Jose Maria Marin (1) ${ }^{2,8}$, \\ Juan Jose Soler-Cataluña ${ }^{9}$ and Bartolome Celli (10 ${ }^{10}$, on behalf of the Scientific \\ Committee of the ANTES programme
}

\begin{abstract}
Affiliations: ${ }^{1}$ Respiratory Institute, Hospital Clinic, Univ. Barcelona, IDIBAPS, Barcelona, Spain. ${ }^{2}$ Centro de Investigación Biomédica en Red Enfermedades Respiratorias (CIBERES), Madrid, Spain. ${ }^{3} \mathrm{AIG}$ de Medicina, Department of Respiratory Medicine, Hospital de Alta Resolución de Loja, Loja, Spain. ${ }^{4}$ Hospital Universitario Son Espases, Universitat de les Illes Balears, Palma de Mallorca, Spain. ${ }^{5}$ Hospital Universitario Quirónsalud Madrid, Madrid, Spain. ${ }^{6}$ Departamento de Medicina y Especialidades, Universidad de Alcalá, Madrid, Spain. ${ }^{7}$ Servicio de Neumología, Hospital Universitario de Guadalajara, Guadalajara, Spain. ${ }^{8}$ Hospital Miguel Servet, University of Zaragoza and IISAragón, Zaragoza, Spain. ${ }^{9}$ Department of Respiratory Medicine, Hospital Arnau de Vilanova-Lliria, Valencia, Spain. ${ }^{10}$ Harvard Medical School, Boston, MA, USA.
\end{abstract}

Correspondence: Alvar Agusti, Respiratory Institute, Hospital Clinic, Villarroel 170, 08036 Barcelona, Spain. E-mail: aagustidelinic.cat

@ERSpublications

COPD is often not diagnosed, or is diagnosed too late. It is time for a change that anticipates both diagnosis and treatment. https://bit.ly/2BrDSv1

Cite this article as: Agusti A, Alcazar B, Cosio B, et al. Time for a change: anticipating the diagnosis and treatment of COPD. Eur Respir J 2020; 56: 2002104 [https://doi.org/10.1183/13993003.02104-2020].

\section{Introduction}

COPD is a major public health problem because of its high prevalence (about $10 \%$ of the adult population), rising incidence (likely related to the ageing of the population), associated morbi-mortality (it is currently the third leading cause of death globally), and personal, social and economic costs [1]. The traditional way to address this problem has been to reduce smoking exposure, the main environmental risk factor for COPD [1]. Although this was, is and will be, a key public-health strategy, we argue here that it is not enough. If we want to eradicate COPD [2], it is time for a change that anticipates the diagnosis and treatment of the disease.

\section{Rationale}

COPD has been traditionally considered a disease of old people, self-inflicted by tobacco smoking [3]. Yet, research over the past few years is changing this paradigm (figure 1). Well-conducted epidemiological studies have shown that close to $30 \%$ of subjects with airflow limitation consistent with COPD have never smoked [4]. Yet, by and large, the evidence available today on the natural history and therapeutic management of COPD focuses almost exclusively on smoking-related COPD, essentially ignoring COPD in never smokers [4]. We also know that there are subjects with similar risk factors and clinical manifestations, but normal spirometry [5]. Likewise, it is clear now that impaired lung development also plays an important role in the pathogenesis of COPD $[6,7]$, that there are many different factors beyond smoking that influence lung function through life (figure 2) [8], and that low lung function in early adulthood is associated with multi-morbidity and premature death [9]. Because undiagnosed patients have 


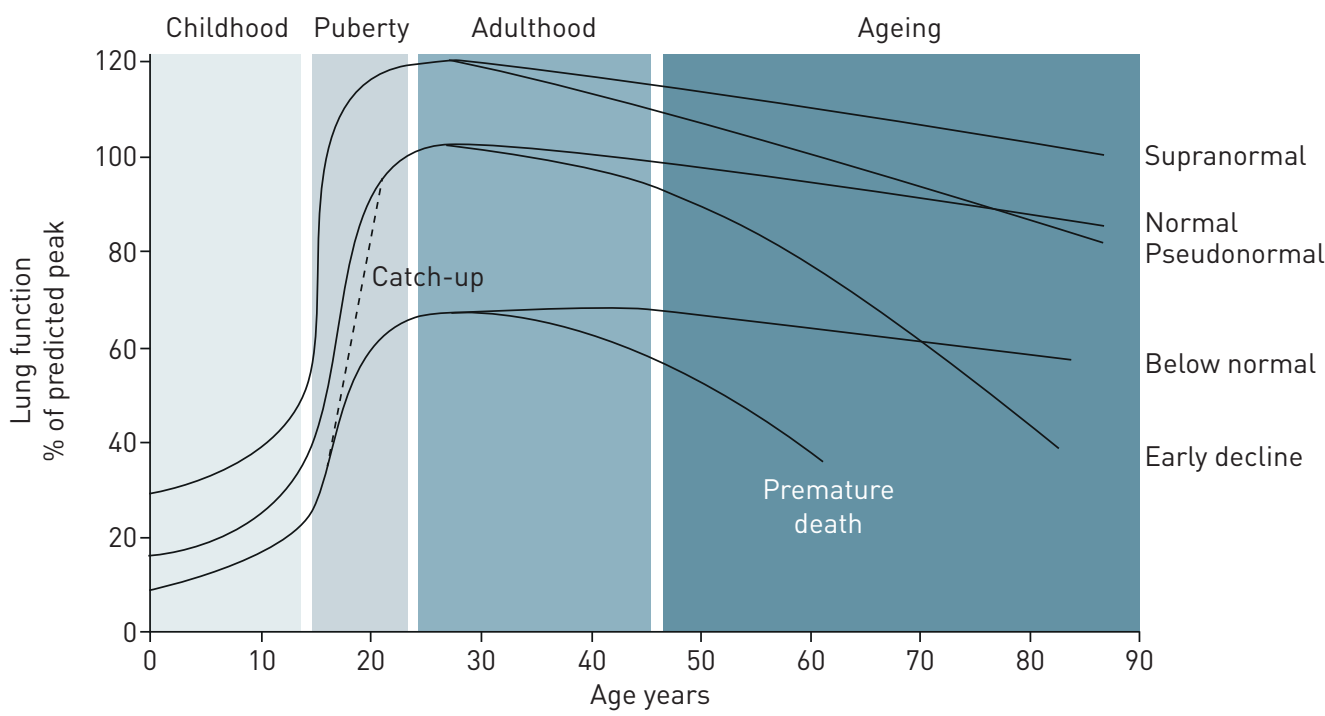

FIGURE 1 Lung function trajectories from birth to death. Both abnormal lung development and an increased rate of lung-function decline with age can lead to COPD in adulthood. These two mechanisms can coexist. For further explanations, see text. Reprinted from [7] with permission from the publisher.

poor outcomes $[10,11]$, anticipating the diagnosis and treatment of COPD is likely to reduce disease burden, both individually and collectively $[12,13]$.

Time for a change: the ANTES programme

To anticipate the diagnosis and treatment of COPD, several centres in Spain have agreed to collaborate on a research initiative named ANTES ("Earlier" in Spanish). Below, we discuss the five initial working areas where to develop specific research projects aimed at achieving the strategic goals of ANTES. Collaborations with other research centres are welcome.

\section{1) Improve COPD underdiagnosis}

Currently, more than $75 \%$ of COPD patients in the community have not been diagnosed, so they may not have been treated adequately [14]. Improving COPD underdiagnosis is therefore a key goal in ANTES. Spirometry is required for the diagnosis of COPD [1]. Although it is noninvasive, inexpensive, reproducible and easy to perform, and despite many years of intensive educational efforts, it is often not used in clinical practice. It is therefore time to implement novel strategies. One involves the use of questionnaires combined with micro-spirometers or peak flow meters [15-17]. Another may take advantage of the built-in microphones that are available in most smartphones to analyse breathing sounds, which may in turn provide lung function estimates [18]. Likewise, there are novel ways that use artificial intelligence to detect COPD on computed tomography scans obtained for different reasons [19]. A final alternative may involve access to lung function centres to refer individuals with respiratory symptoms for spirometry and specialised assessment [20]. All in all, this goes beyond the much debated concept of "COPD" screening [21] and proposes a new approach for "lung health" screening (figure 1) [8, 12], which, as discussed above, is associated with prevention of early comorbidities and premature death [9]. As a result, the current definition and taxonomy of COPD may need to be reconsidered [22].

\section{2) Act earlier}

Over the past few years there has been an increasing interest in the concept of "early" COPD [6, 9, 23-25]. It has been defined, somewhat arbitrarily, as chronic airflow limitation in subjects younger than 50 years exposed to tobacco smoke or other pollutants [26, 27]. Yet, there is evidence that there are detectable structural and functional abnormalities in much younger individuals $[6,8,9,12,25]$. Therefore, efforts should be made to look for younger patients or subjects at risk. Initiatives to test lung function in schools, universities, and during examination for a driving licence [12] are under way in ANTES.

\section{3) Early therapeutic optimisation}

Anticipating the diagnosis and treatment of COPD does not only mean to diagnose and treat "younger" patients with COPD, but also to explore if early therapeutic optimisation results in better outcomes [28]. 


\begin{tabular}{|c|c|c|c|c|c|}
\hline & 6 to $<15$ yrs & 15 to $<30 \mathrm{yrs}$ & 30 to $<45 \mathrm{yrs}$ & 45 to $<60 \mathrm{yrs}$ & 60 to 82 yrs \\
\hline & $n=981$ & $n=2012$ & $n=2404$ & $n=3010$ & $n=2972$ \\
\hline Prevalence pre-BD FEV $1<\mathrm{LLN}$ & $6.6 \%$ & $7.2 \%$ & $7.4 \%$ & $7.5 \%$ & $8.5 \%$ \\
\hline Age & 1.5 & & & & \\
\hline Low education status & & 1.03 & & & \\
\hline Wheezing & & & 3.0 & 2.0 & 1.8 \\
\hline Coughing & & & & 2.0 & \\
\hline Dyspnoea & & & & 2.0 & 2.0 \\
\hline Asthma & 7.5 & 2.8 & 2.9 & & 3.3 \\
\hline COPD/chronic bronchitis & 43.3 & & 2.9 & 3.5 & 4.1 \\
\hline Sinusitis/nasal polyps & & & 4.9 & & \\
\hline Pneumonia, ever & & & & 1.6 & \\
\hline Low fat free mass index & 3.9 & 2.2 & 1.6 & & 2.3 \\
\hline Central obesity & & & & & 1.8 \\
\hline Diabetes & & & & & 2.0 \\
\hline Positive skin prick test & 2.5 & & & & \\
\hline Low hand grip test & & & 1.9 & & \\
\hline Current smoking & NA & & & 1.7 & 1.8 \\
\hline$\geqslant 20$ pack years & NA & 81.8 & & & 2.9 \\
\hline Sugary drinks, >1 per day & & & 1.5 & 1.7 & \\
\hline Fruits/vegetables, <2 per day & & 1.8 & & & \\
\hline High traffic level near home & & & 1.6 & & \\
\hline Parenteral asthma/COPD & & & & & 1.8 \\
\hline Elevated hsCRP & 3.8 & & & & \\
\hline Elevated eosinophils & & & & & 2.1 \\
\hline
\end{tabular}

FIGURE 2 Prevalence of low lung function (forced expiratory volume in $1 \mathrm{~s}\left(\mathrm{FEV}_{1}\right)$ less than the lower limit of normal (LLN)) in different age bins and heatmap of significantly associated factors identified by multivariate regression analysis in the LEAD cohort in Austria. Figures in cells indicate odd ratios (blue, lowest OR; red, highest OR); white cells indicate absence of a significant relationship. NA: not available. Reproduced from [8] with permission from the publisher.

This is a different strategy from current guideline recommendations that propose a step-up approach for the pharmacological management of COPD [1]. For instance, there is evidence that the initial use of dual bronchodilator therapy in patients with mild airflow limitation decreases the rate of lung function deterioration [29]. This is currently being explored further in the on-going RETHINC trial (https:// clinicaltrials.gov/ct2/show/NCT02867761), that compares dual bronchodilation versus placebo in symptomatic smokers without airflow limitation (forced expiratory volume in $1 \mathrm{~s}$ to forced vital capacity ratio $>0.70$ ). Although this trial will not be able to compare dual versus single bronchodilation, it will offer important new knowledge in this setting. Yet, other pragmatic, real-life studies will still be needed in this 
area to define the potential risks and benefits associated with an early therapeutic optimisation strategy. The recent severe acute respiratory syndrome coronavirus 2 pandemic has opened new questions on the potential role of respiratory medications on the outcome of coronavirus disease 2019 patients with COPD that will have to be further investigated [30].

\section{4) Exacerbation zero}

COPD exacerbations worsen health status, accelerate lung function decline, increase mortality and generate important costs [31-33]. Preventing exacerbations is, therefore, a key objective of COPD management [1]. Current recommendations require that the patient should have suffered two or more exacerbations in the previous year (despite appropriate bronchodilator treatment) to escalate therapy in order to prevent future exacerbations [1]. In these patients, the combination of two bronchodilators or the addition of inhaled corticosteroids (ICS), phosphodiesterase- 4 inhibitors or macrolides to one or two bronchodilators reduce the number and severity of future exacerbations [1]. This raises the question on why we must wait until the patient has suffered two or more exacerbations to initiate effective preventive treatment. This approach is not applied in patients with other chronic conditions, such as cardiovascular diseases. In these patients, preventive measures are not delayed until the patient has suffered two acute coronary events or strokes, and we postulate that this should not be the case either in patients with COPD. In ANTES, we argue that we need to be more ambitious and aim for an "exacerbation zero" goal. The ideal way to achieve this ambitious goal would be primary prevention of the disease [12]. Once the disease has developed, though, it may probably need to be reshaped into a "severe exacerbation zero" goal. To this end, several potential strategies may be conceived. First, smoking cessation, regular physical activity, appropriate diet and adequate vaccination [1]. Second, although pharmacology can certainly contribute to it, perhaps we should reconsider the currently recommended strategy [1]. For instance, adding ICS to chronic bronchodilator therapy at the onset of an upper respiratory tract infection decreases the severity of exacerbation that may follow [34]. Unfortunately, the use of personalised risk scores to predict and prevent the likelihood of future exacerbations is not yet ready for prime time [35]. In part, this is related to the lack of objective diagnostic markers of a COPD exacerbation [36]. ANTES envisage to define and validate a definition of COPD exacerbation based on objective, measurable and validated biomarkers as a necessary intermediate step to achieve the "exacerbation zero" goal.

\section{5) Improve survival}

Improving survival is one of the key therapeutic goals of many human chronic diseases [37]. The traditional, nihilistic approach that prognosis cannot be improved in COPD must be abandoned, since several interventions have proven it wrong. Smoking cessation, vaccinations, regular exercise and appropriate dietary programmes must be enforced in all people, including COPD patients, as they all have well known health consequences. Besides, several specific COPD interventions have also shown conclusively to improve survival in these patients, including oxygen supplementation to hypoxaemic COPD patients and lung volume reduction in patients with severe functional limitation and upper lung lobe inhomogeneous emphysema [1]. Likewise, the fact that comorbid diseases, such as cardiovascular diseases and lung cancer [38], are highly prevalent in patients with COPD, and that they are often their cause of death, particularly in patients with mild to moderate airflow limitation [39], pinpoints towards another important area where effective treatment can reduce mortality, so every COPD patient should be evaluated for their presence, because these diseases are treatable. For instance, as indicated by one of the anonymous reviewers of this paper, in patients with COPD and cardiovascular disease, the effectiveness of an early treatment that combines dual bronchodilation and $\beta$-blockade should be assessed.

Respiratory pharmacotherapy using long-acting bronchodilators alone or combined with ICS can also potentially reduce the risk of death in COPD [40]. It is true that the two pharmacological studies that were powered on mortality (TORCH [41] and SUMMIT [42]) did not achieve statistical significance, albeit TORCH was close (the hazard ratio for death in the combination therapy group versus placebo after adjustment for the fact that an interim analyses was done during the course of the study was 0.825 , with 95\% CI 0.681-1.002; $\mathrm{p}=0.052$ ) [41]. Numerically speaking, though, both studies showed a $17.5 \%$ and $12 \%$ relative risk reduction in mortality versus placebo, respectively [41, 42], thus providing some encouraging signal. In fact, other studies where mortality was a secondary outcome, such as the 4-year UPLIFT trial that compared tiotropium versus placebo, did indeed show a benefit in mortality [33]. Further, a numerical reduction in mortality was also seen in a post hoc stratified pooled analysis of the effects of the extra-fine triple combination, albeit differences did not achieve statistical significance except, interestingly, for mortality due to non-respiratory events [43]. Finally, the recent IMPACT study confirmed prospectively that triple combination of ICS/long-acting $\beta$-agonist/long-acting muscarinic antagonist significantly reduced mortality in COPD, albeit mortality was a pre-specified secondary (not primary) outcome of the study [44]. Likewise, very recently, the ETHOS study has confirmed that triple therapy redyces mortality significantly 
in patients with moderate-tovery-severe COPD and at least one exacerbation in the past year [45]. Considered together, these studies suggest that pharmacotherapy may indeed reduce mortality in some selected patients with COPD [40]. It is possible, and ANTES will address this issue, that by identifying the subset of patients most likely to respond and/or prove that a pharmacological intervention may reduce the risk of death in patients with COPD will provide the necessary impetus to develop novel treatment strategies aimed at achieving this ultimate goal [40].

\section{Conclusions}

ANTES is an ambitious, multicentre, research initiative based on the concept that anticipating the diagnosis and treatment of COPD will reduce its public-health impact by improving its prevention, treatment and prognosis.

Acknowledgements: ANTES is supported by GSK and run by an independent academic scientific committee, which includes the authors of this article and, in addition, Julio Ancochea, Ciro Casanova, Alberto Fernandez Villar, Juan Luis Garcia Rivero, Cruz Gonzalez, Jose Luis Lopez Campos, Francisco Javier Martin-Sanchez, Jesus Molina, German Peces-Barba, Miguel Roman and Felipe Villar.

Conflict of interest: A. Agusti reports grants and personal fees from GSK, during the conduct of the study; grants and personal fees for lectures and advisory board work from GSK, Menarini, Chiesi and AZ, personal fees for lectures from Zambon, outside the submitted work. B. Alcazar reports grants and personal fees from GSK, grants, personal fees and non-financial support from Novartis AG and Laboratorios Menarini, personal fees and non-financial support from Boehringer Ingelheim and Chiesi, personal fees from Gebro, AstraZeneca, Laboratorios Rovi and Laboratorios Ferrer, outside the submitted work; and has a patent P201730724 licensed. B. Cosio reports personal fees and non-financial support from GSK, during the conduct of the study; personal fees for lectures from AstraZeneca and Rovi, grants from Boehringer and Menarini, grants and personal fees for lectures from Novartis and Chiesi, personal fees for advisory borad work from Esteve, outside the submitted work. J.M. Echave has nothing to disclose. R. Faner reports grants from GSK and Menarini, outside the submitted work. J.L. Izquierdo reports personal fees from AstraZeneca, Bayer, Boehringer Ingelheim, Chiesi, GSK, Grifols, Menarini, Novartis, Orion, Pfizer, Sandoz and Teva, during the conduct of the study. J.M. Marin has nothing to disclose. J.J. Soler-Cataluña reports personal fees from AstraZeneca, Bial, Rovi and Ferrer, grants, personal fees and non-financial support from Boehringer Ingelheim and Novartis, grants and personal fees from Chiesi and GSK, personal fees and non-financial support from Menarini, outside the submitted work. B. Celli reports grants and provision of research facilities from AstraZeneca, personal fees for consultancy and scientific committee work from GlaxoSmithKline, personal fees for consultancy from Boehringer Ingelheim, Novartis, Sanofi Aventis, Chiesi, Pulmonx and Menarini, outside the submitted work.

\section{References}

1 Global Initiative for Chronic Obstructive Lung Disease. Global strategy for the diagnosis, management, and prevention of Chronic Obstructive Pulmonary Disease. 2020. www.goldcopd.org

2 Dransfield M, Stolz D, Kleinert S. Towards eradication of chronic obstructive pulmonary disease: a Lancet Commission. Lancet 2019; 393: 1786-1788.

3 Fletcher C, Peto R. The natural history of chronic airflow obstruction. Br Med J 1977; 1: 1645-1648.

4 Salvi SS, Barnes PJ. Chronic obstructive pulmonary disease in non-smokers. Lancet 2009; 374: 733-743.

5 Woodruff PG, Barr RG, Bleecker E, et al. Clinical significance of symptoms in smokers with preserved pulmonary function. N Engl J Med 2016; 374: 1811-1821.

6 Lange P, Celli B, Agusti A, et al. Lung-function trajectories leading to chronic obstructive pulmonary disease. N Engl J Med 2015; 373: 111-122.

7 Agusti A, Hogg JC. Update on the pathogenesis of chronic obstructive pulmonary disease. N Engl J Med 2019; 381: 1248-1256.

8 Breyer-Kohansal R, Faner R, Breyer M-K, et al. Factors associated with low lung function in different age bins in the general population. Am J Respir Crit Care Med 2020; 202: 292-296.

9 Agustí A, Noell G, Brugada J, et al. Lung function in early adulthood and health in later life: a transgenerational cohort analysis. Lancet Respir Med 2017; 5: 935-945.

10 Martinez CH, Mannino DM, Jaimes FA, et al. Undiagnosed obstructive lung disease in the United States. Associated factors and long-term mortality. Ann Am Thorac Soc 2015; 12: 1788-1795.

11 Labonté LE, Tan WC, Li PZ, et al. Undiagnosed chronic obstructive pulmonary disease contributes to the burden of health care use. Data from the CanCOLD Study. Am J Respir Crit Care Med 2016; 194: 285-298.

12 Agusti A, Faner R. COPD beyond smoking: new paradigm, novel opportunities. Lancet Respir Med 2018; 6: 324-326.

13 Faner R, Agusti A. Global lung health: the dangers of mild lung function impairment. Lancet Glob Health 2019; 7: e542-e543.

14 Lamprecht B, Soriano JB, Studnicka M, et al. Determinants of underdiagnosis of COPD in national and international surveys. Chest 2015; 148: 971-985.

15 Sierra VH, Hernandez MA, Cobos LP, et al. Usefulness of the Piko-6 portable device for early COPD detection in primary care. Arch Bronconeumol 2018; 54: 460-466.

16 Represas CR, Rial MB, Fernandez VL, et al. [Assessment of the portable COPD-6 device for detecting obstructive airway diseases]. Arch Bronconeumol 2010; 46: 426-432.

17 Martinez FJ, Mannino D, Leidy NK, et al. A new approach for identifying patients with undiagnosed chronic obstructive pulmonary disease. Am J Respir Crit Care Med 2017; 195: 748-756.

18 Larson EC, Goel M, Boriello G, et al. SpiroSmart: using a microphone to measure lung function on a mobile phone. UbiComp '12: Proceedings of the 2012 ACM Conference on Ubiquitous Computing. Pittsburgh, ACM, 2012; pp. 280-289. 
19 Tang LYW, Coxson HO, Lam S, et al. Towards large-scale case-finding: training and validation of residual networks for detection of chronic obstructive pulmonary disease using low-dose CT. Lancet Digital Health 2020; 2: e259-e267.

20 Vargas C, Burgos F, Cano I, et al. Protocol for regional implementation of collaborative lung function testing. NPJ Prim Care Respir Med 2016; 26: 16024.

21 Lambe T, Adab P, Jordan RE, et al. Model-based evaluation of the long-term cost-effectiveness of systematic case-finding for COPD in primary care. Thorax 2019; 74: 730-739.

22 Celli BR, Agustí A. COPD: time to improve its taxonomy? ERJ Open Res 2018; 4: 00132-2017.

23 Soriano JB, Polverino F, Cosio BG. What is early COPD and why is it important? Eur Respir J 2018; 52: 1801448.

24 Agusti A, Faner R, Donaldson G, et al. Chronic Airway Diseases Early Stratification (CADSET): a new ERS Clinical Research Collaboration. Eur Respir J 2019; 53: 1900217.

25 Çolak Y, Afzal S, Nordestgaard BG, et al. Prevalence, characteristics, and prognosis of early chronic obstructive pulmonary disease. The Copenhagen General Population Study. Am J Respir Crit Care Med 2020; 201: 671-680.

26 Martinez FJ, Han MK, Allinson JP, et al. At the root: defining and halting progression of early chronic obstructive pulmonary disease. Am J Respir Crit Care Med 2018; 197: 1540-1551.

27 Agusti A, Faner R. How to define early chronic obstructive pulmonary disease. Am J Respir Crit Care Med 2018: 198: 973.

28 Agusti A, Dekhuijzen PR. Maximal bronchodilation: a therapeutic target in COPD? Lancet Respir Med 2017; 5: 540-542.

29 Maltais F, Bjermer L, Kerwin EM, et al. Efficacy of umeclidinium/vilanterol versus umeclidinium and salmeterol monotherapies in symptomatic patients with COPD not receiving inhaled corticosteroids: the EMAX randomised trial. Respir Res 2019; 20: 238 .

30 Halpin DMG, Faner R, Sibila O, et al. Do chronic respiratory diseases or their treatment affect the risk of SARS-CoV-2 infection? Lancet Respir Med 2020; 8: 436-438.

31 Seemungal TA, Donaldson GC, Paul EA, et al. Effect of exacerbation on quality of life in patients with chronic obstructive pulmonary disease. Am J Respir Crit Care Med 1998; 157: 1418-1422.

32 Wilkinson TM, Patel IS, Wilks M, et al. Airway bacterial load and FEV1 decline in patients with chronic obstructive pulmonary disease. Am J Respir Crit Care Med 2003; 167: 1090-1095.

33 Soler-Cataluna JJ, Martinez-Garcia MA, Roman Sanchez P, et al. Severe acute exacerbations and mortality in patients with chronic obstructive pulmonary disease. Thorax 2005; 60: 925-931.

34 Stolz D, Hirsch HH, Schilter D, et al. Intensified therapy with inhaled corticosteroids and long-acting $\beta 2$-agonists at the onset of upper respiratory tract infection to prevent chronic obstructive pulmonary disease exacerbations. A multicenter, randomized, double-blind, placebo-controlled trial. Am J Respir Crit Care Med 2018; 197: $1136-1146$.

35 Guerra B, Gaveikaite V, Bianchi C, et al. Prediction models for exacerbations in patients with COPD. Eur Respir Rev 2017; 26: 160061.

36 Agusti A, Faner R, Celli B, et al. Precision medicine in COPD exacerbations. Lancet Respir Med 2018; 6: 657-659.

37 Rosenbaum L, Lamas D. Facing a "Slow-Motion Disaster" - The UN Meeting on Noncommunicable Diseases. N Engl J Med 2011; 365: 2345-2348.

38 Divo M, Cote C, de Torres JP, et al. Comorbidities and risk of mortality in patients with chronic obstructive pulmonary disease. Am J Respir Crit Care Med 2012; 186: 155-161.

39 Sin DD, Anthonisen NR, Soriano JB, et al. Mortality in COPD: role of comorbidities. Eur Respir J 2006; 28 : $1245-1257$

40 Celli B, Divo M, Plata VP. Pharmacotherapy impacts on COPD mortality. Arch Bronconeumol 2020; in press [https://doi.org/10.1016/j.arbres.2020.03.030].

41 Calverley PMA, Anderson JA, Celli B, et al. Salmeterol and fluticasone propionate and survival in chronic obstructive pulmonary disease. N Engl J Med 2007; 356: 775-789.

42 Vestbo J, Anderson JA, Brook RD, et al. Fluticasone furoate and vilanterol and survival in chronic obstructive pulmonary disease with heightened cardiovascular risk (SUMMIT): a double-blind randomised controlled trial. Lancet 2016; 387: 1817-1826.

43 Vestbo J, Fabbri L, Papi A, et al. Inhaled corticosteroid containing combinations and mortality in COPD. Eur Respir J 2018; 52: 1801230.

44 Lipson DA, Crim C, Criner GJ, et al. Reduction in all-cause mortality with fluticasone furoate/umeclidinium/ vilanterol in COPD patients. Am J Respir Crit Care Med 2020; 201: 1508-1516.

45 Rabe KF, Martinez FJ, Ferguson GT. Triple inhaled therapy at two glucocorticoid doses in moderate-to-very-severe COPD. N Engl J Med 2020; 383: 35-48. 